\title{
Molecular Markers for Long-term Survival in Stage IIIA (N2) NSCLC Patients
}

\author{
ANCA NASTASE ${ }^{1}$, SIMONA O. DIMA ${ }^{1}$, AUDREY LUPO ${ }^{2}$, VICTORIA LASZLO ${ }^{1}$, REBECCA TAGETT $^{3}$, \\ SORIN DRAGHICI ${ }^{1}$, MONICA ELIA GEORGESCU ${ }^{4}$, ALEXANDRU NECHIFOR $^{4}$, SORIN BERBECE ${ }^{4}$, \\ IRINEL POPESCU $^{1}$, MARCO ALIFANO $^{2}$, WALTER KLEPETKO ${ }^{5}$ and MADALINA GRIGOROIU ${ }^{1}$ \\ ${ }^{1}$ Center of Digestive Diseases and Liver Transplantation, Fundeni Clinical Institute, Bucharest, Romania; \\ ${ }^{2}$ Hôpital Cochin, AP-HP, Université de Paris, Paris, France; \\ ${ }^{3}$ Intelligent Systems and Bioinformatics Laboratory (ISBL), \\ Department of Computer Science, Wayne State University, Detroit, MI, U.S.A.; \\ ${ }^{4}$ Dunarea De Jos University, Faculty of Medicine and Pharmacy, Galati, Romania; \\ ${ }^{5}$ Department of Thoracic Surgery, Vienna General Hospital, Vienna, Austria
}

\begin{abstract}
Background: Survival rates among non-small cell lung cancer (NSCLC) stage IIIA (N2) patients are generally low and depend on the treatment. Patients and methods: We aimed to identify predictive markers for long term survival in responders and non-responders to chemotherapy, analyzing tumour and non-tumour samples by microarray $(n=35)$ and whole exome sequencing (WES, $n=25$ ). Results: WES data showed correlation of overall survival of all patients with rs9905892 in the SLFN12L gene. High frequency of mutations $(4 / 6,66.7 \%)$ was identified in members of SWI/SNF complex in responder patients and in patients that were alive after seven years. Microarray data for immune components showed that VISTA (VSIR) was down-regulated in tumoral tissue. Conclusion: Our research suggests that mutations in SWI/SNF complex associate with long term survival after multimodal treatment, while down-regulation of VISTA might indicate its immunomodulatory role in NSCLC stage III (N2) patients.
\end{abstract}

Patients with stage IIIA (N2) non-small cell lung cancer (NSCLC) are a heterogeneous group. Ruckdeschel et al. (1) divides these patients into three groups: $\mathrm{N} 2$ lymph nodes with minimum or microscopic invasion, randomly detected during or after surgical intervention; N2 lymph nodes detected before

This article is freely accessible online.

Correspondence to: Madalina Grigoroiu, MD, Ph.D., Fundeni Clinical Institute, Soseaua Fundeni, No. 258, Sector 2, 022328 Bucharest, Romania. Tel/Fax: +40 213180417, e-mail: madalina.grigoroiu@gmail.com

Key Words: Whole-exome sequencing, platinum sensitivity, NSCLC. the surgical intervention either by imaging or surgery, and patients with massive N2 lymph nodes from multiple lymph node stations. Several treatment strategies have been suggested for stage IIIA NSCLC patients during the past two decades (2), including chemotherapy or neoadjuvant chemoradiotherapeutic treatment followed by surgery, primary surgery followed by adjuvant chemotherapy, with or without sequential radiotherapy, and definitive chemo-radiotherapy without surgical intervention (3-5).

Multiple phase II and III clinical trials proved the clinical practicality and improved survival of neoadjuvant chemotherapy (3, 5-12). In many of these studies, the downstaging of the lymph nodes and complete surgical resection are predictors of long-term survival $(6,7,13)$.

The global 5-year survival of the N2 NSCLC patients is 20$25 \%$ but analysing the patients' subgroups, the 5-year survival is $42 \%$ for those responding to chemotherapy and $10 \%$, respectively, for those without chemotherapeutic response (14).

In our previous study (15), we performed microarray experiments on tumoral and non-tumoral tissue samples derived from tumoral and non-tumoral mediastinal lymph node surgically removed before neoadjuvant chemotherapy treatment from 27 patients with stage IIIA (N2) NSCLC. Based on the response to neoadjuvant chemotherapy, patients were divided in two groups: non-responders (group A), patients with progression or pathological confirmation of persistent mediastinal disease and responders (group B), patients with pathological confirmation of mediastinal down staging. A total of 1,127 genes were identified with modified expression in tumoral tissue compared to normal tissue at $p \leq 0.05$ and 44 genes at $p \leq 0.01$ (15). Genes with the highest difference in gene expression identified between tumoral versus non-tumoral tissue included collagen, type I, alpha 1 (COL1Al), inhibin beta A (INHBA) and thioredoxin 
interacting protein $(T X N I P)$. There were no differentially expressed genes between responders versus non-responders, but the main pathways differentially expressed between groups were cytokine pathways, focal adhesion or extracellular matrix receptor interaction. We also performed whole-exome sequencing (WES) of preoperative tumoral samples from 16 patients (16) and identified SNPs that associated with response to chemotherapy in NSCLC stage IIIA (N2). A higher alternative allele frequency was found on SENP5, rs63736860, rs 1602 and $N C B P 2$, rs553783 in the non-responder group, and on $R G P 1$, rs1570248, SLFN12L, rs2304968, rs9905892, and $G B A 2$, rs3833700 in the responder group.

In the present study, we aimed to identify predictive markers for long term survival in patients with stage IIIA (N2) NSCLC, by retrospectively analyzing microarray ( $n=35$ samples) and whole-exome sequencing (WES, $n=25$ samples) data.

\section{Patients and Methods}

Patient groups. The patient inclusion and exclusion criteria have already been published in extenso $(15,16)$.

Microarray experiments and quality control. Total RNA sample preparation and microarray workflow are already described (15). A total of 25 preoperative tumour samples (lymph nodes) from 27 patients together with 10 normal samples (lymph nodes) were analyzed by microarray (for two patients only normal samples were included).

Whole-exome sequencing (WES). Genomic DNA samples preparation and analysis by whole-exome sequencing (WES) has been described previously (16). A total of 25 samples from 17 patients were sequenced consisting in 16 preoperative tumour samples (lymph nodes), two preoperative normal lymph nodes, 3 postoperative normal samples (normal lung) and 4 postoperative tumour samples (tumour lung). Compared to our previous study, in this analysis, we have included additional non-tumor and postoperative tumour samples for further comparison. WES analysis of the initial 16 preoperative tumour samples showed that there was no difference between the total number of SNPs and Indels between group A $(n=10)$ and group B $(n=6)$ (Figure 1A and B).

Statistical and survival analysis. Overall survival was calculated from the moment of diagnosis until the moment of death or the last follow up (31 ${ }^{\text {st }}$ December 2019). Survival analyses were performed using the long-rank Kaplan-Meier and the differences in survival curves were assessed by the Mantel Cox Log rank test. Test and graphs were done using SPSS Statistics 25, R studio and GraphPad Prism 5. Un-paired $t$-tests and the Benjamini-Hochberg correction with a $p$-Value $<0.05$ and a fold change $\geq 2$ were used for the analysis of microarray data.

Within this study, we ran multiple types of analysis. First, we analysed the status of the alternative alleles of $S N E P 5$, rs63736860, rs 1602, NCBP, rs553783, RGP1, rs1570248, SLFN12L, rs2304968, rs 9905892 , and $G B A 2$, rs 3833700 in samples that were sequenced with emphasis on samples from patients that constituted the alive patients group. Secondly, we wanted to identify mutations in wellestablished NSCLC driver genes and to determine if these genes might be responsible for the patients' long term survival. Thirdly, we compared gene expression of the genes with mutations between tumour and normal samples, as well as gene expression of different components of the immune system.

\section{Results}

Patient characteristics. Among the 73 patients initially included, there were 28 patients eventually treated with multimodal therapy (neoadjuvant chemotherapy followed by definitive chemo-radiotherapy if progression was detected after neoadjuvant chemotherapy evaluation or by surgery and adjuvant chemotherapy or chemo-radiotherapy for the others). One patient was excluded from tissue sample analysis because of bad sample quality. The last patient was included on December 3, 2012. At the end of the follow up, on December 31, 2019, 5 patients were still alive, 20 patients were deceased and 2 patients were lost to follow-up. These two patients were classified as non-responders.

The 5-year survival. In the non-responder group (group A, $n=20)$ the 5 -year survival is $11.1 \%$, the average survival was 37.4 months (95\% CI=25.3-51.2) and the median survival was 37 months, while in the responders group (group B, $n=7$ ), the 5 -year survival was $42.9 \%$, the average survival was 61 months (95\% CI=35.2-91.8) and the median survival was 54 months. There was no statistical difference in overall survival between group A and B patients (Figure 1C). The median survival among deceased patients in non-responders (group A, $n=16$ ) was 26 months and the average survival was 30.3 months $(95 \%$ $\mathrm{CI}=21.4-39.2$ ), while in responders (group B, $n=4$ ) the median survival was 28 and the average survival was 31.7 months (95\% CI=16.1-47.9). There was no statistical difference in overall survival between group A and B patients (Figure 1D).

Non-responders group (group A). There were 20 patients, 12 males and 8 females, with a median age of 61.5 years and an average of 60.75 years (39-74 years old). At the end of the follow up (December 31, 2019), 2 patients were still alive, 16 patients were deceased and 2 were lost to follow up. There were 17 patients with adenocarcinoma (ADK), 2 patients with squamous lung cancer (SCC) and one patient with large cell neuroendocrine (LCNE) lung cancer. After neoadjuvant chemotherapy, seven patients were stabilized at re-evaluation and had a lung resection. For three patients the tumor on the resected specimen was slightly bigger than measured on the initial CT scan (before treatment), one patient had a pleural carcinosis, two patients were stable compared with initial CT scanner and only one patient had a smaller tumor.

Responders group (group B). There were seven patients with pathological confirmed mediastinal downstage, six males and one female, both median and average of 62 years (55-73 years old). At the end of the follow up (December 31, 2019), three 
A
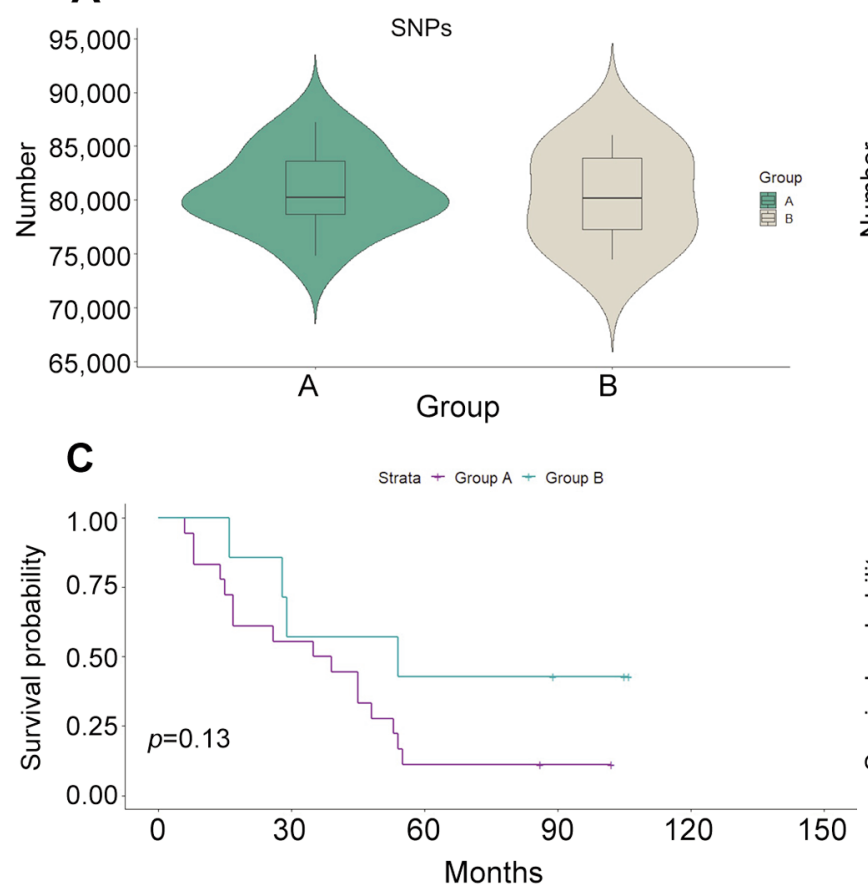

B
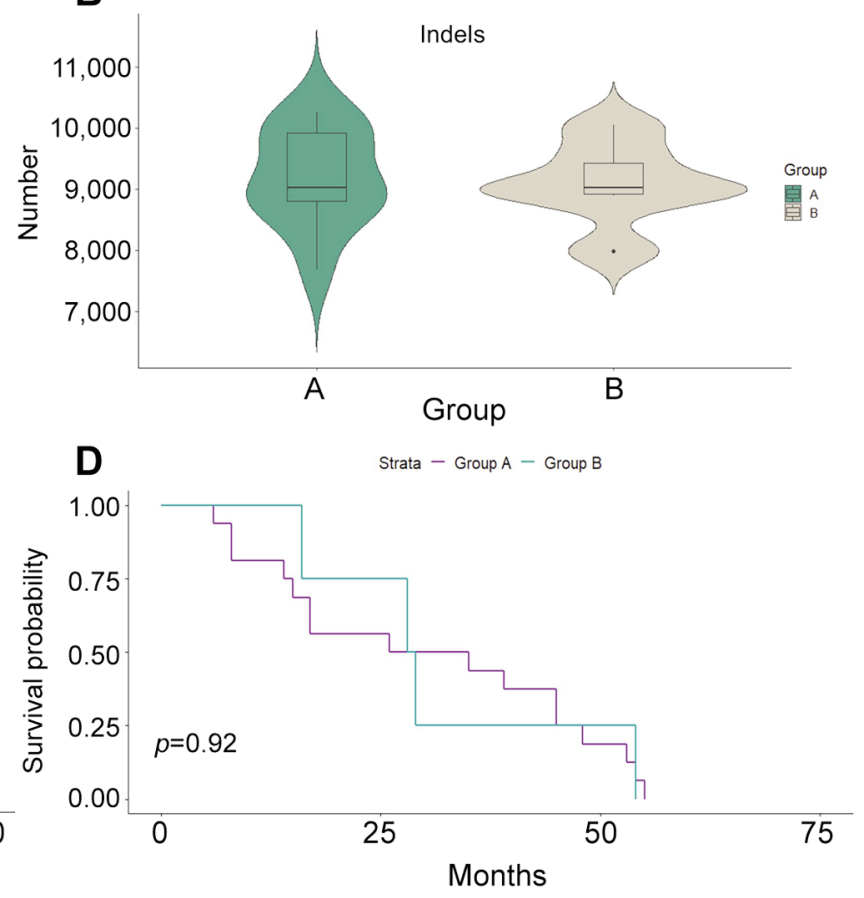

Figure 1. Analysis of patients based on response to therapy. A) Violin plots showing the number of SNPs in group A ( $n=10)$ and $B(n=6) ; B)$ Violin plots showing the number of Indels in group $A(n=10)$ and $B(n=6) ; C)$ Kaplan-Meier survival curve in Group $A(n=18)$ vs Group B (n=7); D) Kaplan-Meier survival curve in Group A $(n=16)$ vs Group B $(n=4)$ for the deceased patients group.

patients were still alive and four patients were deceased. There were five patients with adenocarcinoma and two patients with large cell neuroendocrine carcinomas. After neoadjuvant chemotherapy, all patients were stabilized at re-evaluation and went through a lung resection. Pathological examination on lung resected specimen and complete mediastinal lymphadenectomy confirmed the mediastinal downstaging for all the patients and noted a complete response for two patients. The TNM stages before treatment and after pathological examination on lung resected specimens are shown on Table I.

Alive group. A total of five patients were still alive at the end of the follow up. Survival ranged from 86 to 106 months. There were three males and two females, with a median age of 58 years and an average of 59 years (55- 66 years old). Three patients were responders (group B) and two were nonresponders (group A). Table II shows the detailed clinical information for these patients (samples from all five patients were analysed by microarray, while samples from three patients were analysed by WES).

Evaluation of genetic polymorphisms associated with chemotherapy response in preoperative and postoperative samples and in the alive patients group. A total of seven SNPs were identified to segregate between group A and B of
Table I. TNM stages before and after neoadjuvant chemotherapy for Responders (group B).

\begin{tabular}{lccc}
\hline $\begin{array}{l}\text { Group B } \\
\text { patients }\end{array}$ & cTNM & pTNM & $\begin{array}{c}\text { Histological type } \\
\text { of lung cancer }\end{array}$ \\
\hline 1 & T1aN2 & T0N0 & ADK \\
2 & T1aN2 & T0N0 & ADK \\
3 & T1bN2 & T1aN0 & LCNE \\
4 & T2aN2 & T1bN0 & ADK \\
5 & T3N2 & T2bN0 & ADK \\
6 & T3N2 & T1bN1 & LCNE \\
7 & T3N2 & T1aN0 & ADK \\
\hline
\end{tabular}

ADK: Adenocarcinoma; LCNE: large cell neuroendocrine carcinoma.

patients (16) in 16 patients analyzed by WES. For this analysis, we have also included postoperative samples when available (either non-tumour or tumour samples). The oncoplots showing genotypes of these seven SNPs in pre and postoperative samples, as well as in the alive patients' group are shown in Figure 2A and B, respectively. Kaplan-Meier survival curves showed that SNP rs9905892 in SLFN12L gene, when homozygous for the alternative allele, is associated with survival and rs2304968 in the same gene is 
Table II. Details for patients from the alive group.

\begin{tabular}{lcccccc}
\hline Survival patients & Gender & Age & Prognostic group & cTNM & pTNM & Histological type of lung cancer \\
\hline $1^{*}$ & $\mathrm{M}$ & 56 & $\mathrm{~A}$ & T2aN2 & T2aN2 & ADK \\
2 & $\mathrm{~F}$ & 60 & $\mathrm{~A}$ & T1aN2 & T2bN2 & ADK \\
$3 *$ & $\mathrm{M}$ & 66 & $\mathrm{~B}$ & T1aN2 & T0N0 & LCNE \\
$4^{*}$ & $\mathrm{M}$ & 58 & $\mathrm{~B}$ & T1bN2 & T1aN0 & ADK \\
5 & $\mathrm{~F}$ & 55 & $\mathrm{~B}$ & T1aN2 & T0N0 & ADK \\
\hline
\end{tabular}

ADK: Adenocarcinoma; LCNE: large cell neuroendocrine carcinoma; *WES data available.

marginally associated with survival (Figure 2C and D). In the alive patients group, both SNPs were also present as homozygous for the alternative allele, indicating a possible association between genotype and overall survival for these two SNPs. There was no statistically significant difference in gene expression for $S L F N 12 L$ between tumor and normal samples in the microarray data (Table III).

Mutation in lung cancer drivers in the alive patient group Our analysis focused on identifying mutations in genes known to be associated with NSCLC, led to detecting variants that are present exclusively in non-responders (group A) or only in responders (group B), and variants that are shared by both groups (Figure 2E). The oncoplot in Figure 2E includes matched postoperative samples, when these were available.

TP53 was most frequently altered in both groups $(9 / 16$ patients, $56.25 \%$ ). A frequency of $60.0 \%$ (6/10 patients) was detected in group A, with variants located either in the DNA binding domain or in the trans-activation domain, except one (Figure 3A) and 50\% (3/6 patients) in group B, with two mutations in the trans-activation domain and a third located adjacent to this domain. There was no association between the presence of TP53 mutations and overall survival (Figure 3C) neither for the whole cohort nor when comparing adenocarcinoma histology only.

The second most common mutated gene was SMARCA4 together with the alternative ATPase in the SWI/SNF complex, SMARCA2 (Figure 2E). The frequency of mutations was $10 \%$ (1/10 patients) in group A and 50\% (3/6 patients) in group B, with one patient from this group having a SMARCA2 mutation. Figure $3 \mathrm{~B}$ shows distribution of mutations in SMARCA4. Interestingly, in our study 2/4 mutations in SMARCA4 were found in the alive patients' group, one mutation being present in a large cell neuroendocrine carcinoma patient. This patient also had a $R B 1$ frameshift insertion. No correlation between SMARCA2/4 status and overall survival was observed in our cohort (Figure 3D), probably because of the small number of patients analyzed.

Similar to the study of Schoenfeld et al. (17), we have classified the mutations in SMARCA2 and 4 in Class 1 (truncating, frame shift, slice site) mutations and Class 2 (missense) mutations. Although the number of the patients in our cohort was low, we noticed that the patient from group B with a Class 2 mutation was alive at the end of the follow up and had the longest survival (106 months) (Figure 3E).

In addition, survival analysis with KMPlotter (18) showed that SMARCA4 high gene expression was associated with better survival in adenocarcinoma patients of all stages, but not in squamous cell carcinoma (Figure 4A and B). Survival analysis on stages showed that significance was reached when analyzing adenocarcinoma stage I and II patients ( $p$ Value $=4.3 * 10^{-8}$ and 0.0002 , respectively) and stage II squamous cell carcinoma ( $p$-Value $=0.04)$. The same trend was observed for SMARCA2; high gene expression was associated with better survival in adenocarcinoma patients of all stages, but not in squamous cell carcinoma patients (Figure 4C and D).

As reported before $(19,20)$, no alterations in $E G F R, A L K$, ROS1 or BRAF were observed in patients with $S M A R C A 2 / 4$ mutations, making these genes mutually exclusive in our cohort. This result confirms a previous study that suggested that alterations in SMARCA4 (BRG1) are involved in the progression of EGFR wild type tumors (21). In the whole cohort, SMARCA4 co-occurred with TP53 mutations in two patients.

One patient from group $\mathrm{B}$ had an ARIDIA mutation, which is also a component of the SWI/SNF complex. No survival data was available for this patient. Taken together, mutations in this complex were the most frequent among group B patients.

Analysis of gene expression data in tumour versus normal tissues. Microarray data was available for 35 tissues (eight patients had paired normal and tumor tissues available). Results of differential gene expression for the genes identified to carry mutations in our cohort are shown in Table III. ATM showed a strong down-regulation in tumour tissues compared with normal tissues.

Based on observations from our previous report (15), showing involvement of immune pathways when analyzing the groups of patients, we investigated gene expression of genes 
A

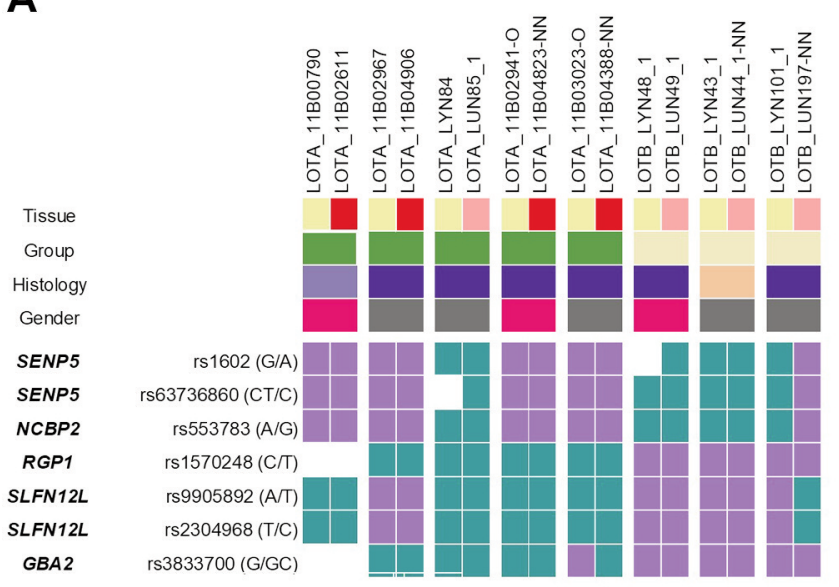

B

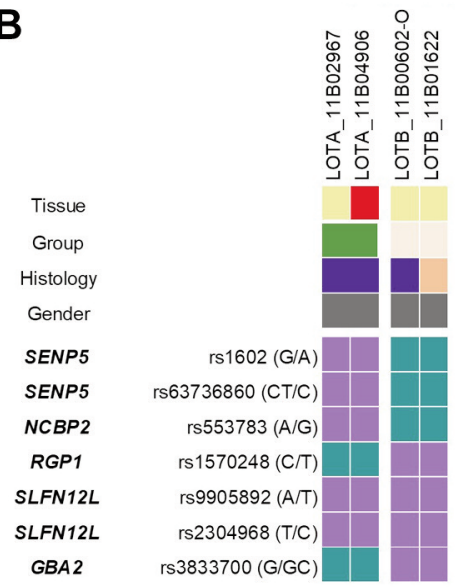

C

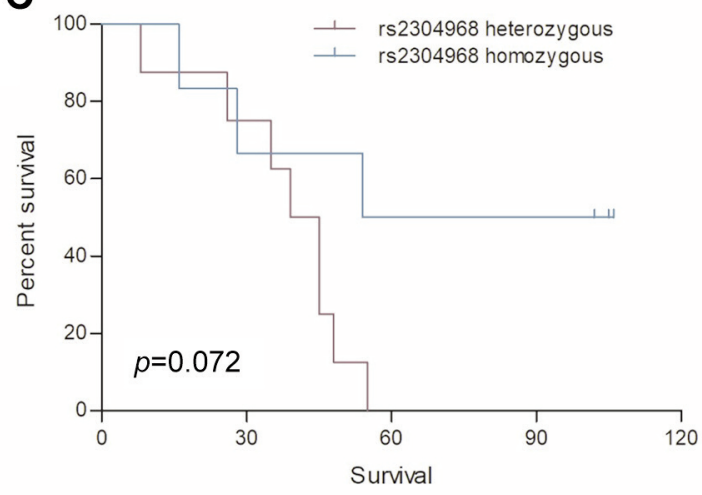

D

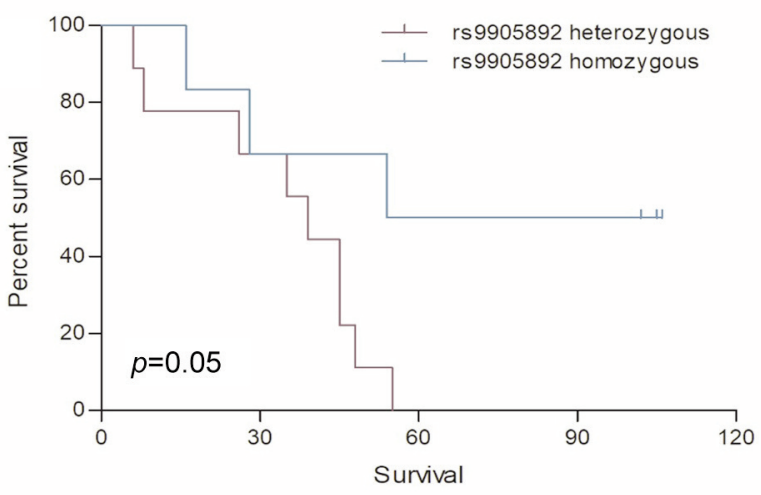

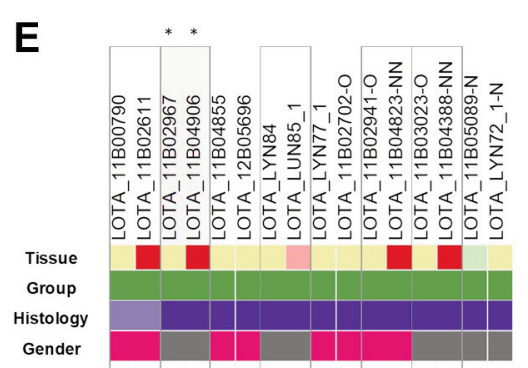

TP53

SMARCA $2 / 4$

KEAP1

EGFR

TERT

STK11

ATM

KIF2OB

KRAS

MET

RET
ARID1A

$R B 1$
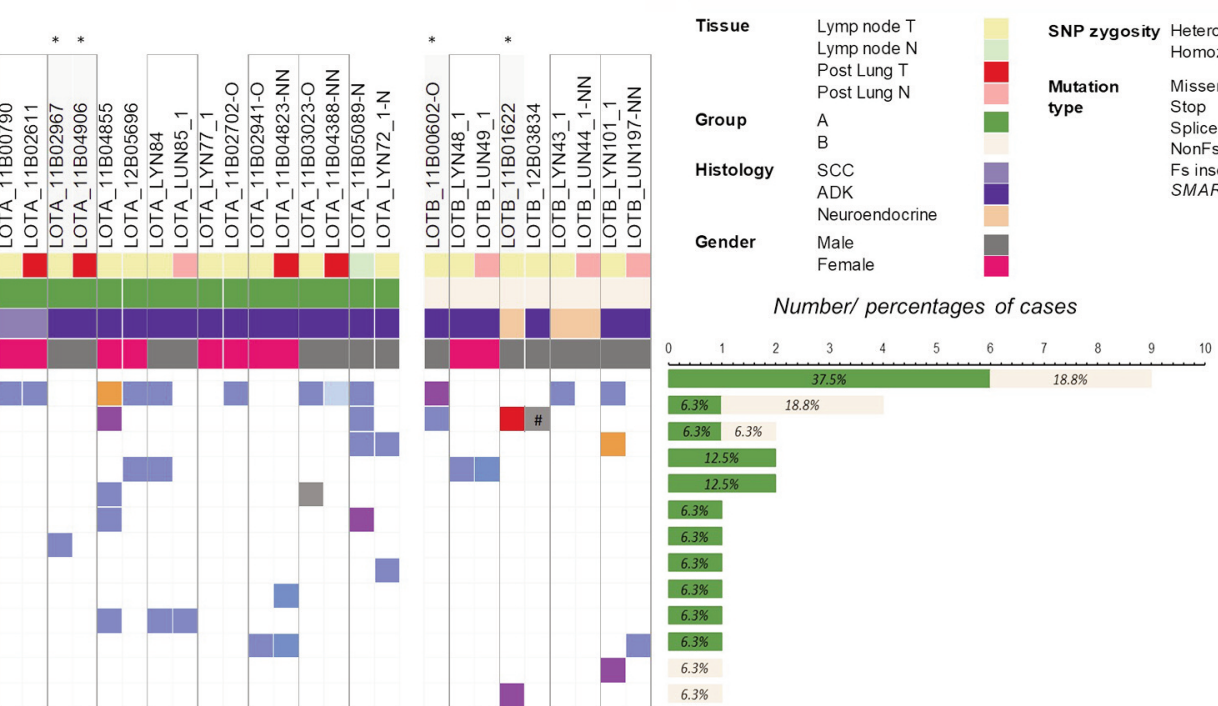

Figure 2. Genomic characterization of the patients. A) Oncoplot for 7 SNPs identified to segregate between group A and B in pre and postoperative samples; B) Oncoplot for 7 SNPs identified to segregate between group A and B in the alive patients group; C) Kaplan-Meier survival curve for rs2304968 (SLFN12L); D) Kaplan-Meier survival curve for rs9905892 (SLFN12L); Note: homozygous=for alternative allele; E) Oncoplot for main driver genes in lung cancer; samples highlighted in grey and marked with star $\left(^{*}\right)$ are from alive patients group; variants were counted only if they were present in tumor and somatic and were counted once if they were present in both pre and postoperative tumor tissue; percentages were calculated considering the total number of patients for each group, if a tumor sample was sequenced (10 for group A, 6 for group B and 16 in total). ADK: Adenocarcinoma; SCC: squamous cell carcinoma. 
Table III. Gene expression of drivers in lung cancer.

\begin{tabular}{|c|c|c|c|c|c|c|c|}
\hline Gene & $\begin{array}{l}\text { Entrez } \\
\text { gene }\end{array}$ & $\log \mathrm{FC}$ & $\begin{array}{l}\text { Average } \\
\text { expression }\end{array}$ & $\mathrm{t}$ & $p$-Value & $\begin{array}{c}\text { Adjusted } \\
p \text {-Value }\end{array}$ & B \\
\hline ATM & 472 & -0.90102 & 7.935319 & -7.30792 & $1.4849798909919 \mathrm{e}-08$ & $2.3708520019991 \mathrm{e}-06$ & 9.618263 \\
\hline SMARCA2 & 6595 & -0.60098 & 8.607164 & -4.31207 & 0.000124 & 0.001484784 & 0.907276 \\
\hline MET & 4233 & 2.093868 & 10.38968 & 4.039216 & 0.000277 & 0.002745748 & 0.1451 \\
\hline$E G F R$ & 1956 & 0.478467 & 6.678288 & 2.640874 & 0.012248 & 0.047791599 & -3.38876 \\
\hline TP53 & 7157 & -0.22243 & 6.737093 & -2.11726 & 0.041374 & 0.117384253 & -4.4675 \\
\hline$R B 1$ & 5925 & -0.24887 & 9.985075 & -2.0274 & 0.050245 & 0.134956071 & -4.63467 \\
\hline STK11 & 6794 & -0.37793 & 10.08338 & -1.75618 & 0.087756 & 0.201991642 & -5.10381 \\
\hline$R E T$ & 5979 & -0.16953 & 6.336739 & -1.73129 & 0.092156 & 0.209113343 & -5.14407 \\
\hline CFTR & 1080 & 0.563947 & 6.281767 & 1.393682 & 0.17215 & 0.3265154 & -5.64111 \\
\hline KIF $20 B$ & 9585 & 0.203065 & 6.954404 & 1.121416 & 0.269702 & 0.443290407 & -5.97148 \\
\hline KEAP1 & 9817 & 0.15342 & 9.309082 & 0.979024 & 0.334249 & 0.51128924 & -6.11776 \\
\hline SMARCA4 & 6597 & 0.354979 & 13.0775 & 0.671583 & 0.506233 & 0.667975504 & -6.36881 \\
\hline TERT & 7015 & 0.134418 & 6.837413 & 0.575984 & 0.56829 & 0.71580937 & -6.42834 \\
\hline ARIDIA & 8289 & -0.06633 & 7.74712 & -0.40652 & 0.686825 & 0.803982118 & -6.51178 \\
\hline
\end{tabular}

Log FC: Log2(fold change); adjusted $p$-value: FDR (false discovery rate) $p$-value adjustment; B: B-statistics (log-odds that that gene is differentially expressed).

Table IV. Gene expression of immune system components.

\begin{tabular}{|c|c|c|c|c|c|c|c|}
\hline Gene & $\begin{array}{l}\text { Entrez } \\
\text { gene }\end{array}$ & $\log \mathrm{FC}$ & $\begin{array}{l}\text { Average } \\
\text { expression }\end{array}$ & $\mathrm{t}$ & $p$-Value & $\begin{array}{c}\text { Adjusted } \\
p \text {-Value }\end{array}$ & B \\
\hline$C D 28$ & 940 & -0.82882 & 7.031805 & -5.50289 & $3.43298869030623 \mathrm{e}-06$ & $9.98932395375382 \mathrm{e}-05$ & 4.357337 \\
\hline VSIR & 64115 & -0.82534 & 10.18157 & -4.71127 & $3.78181154525982 \mathrm{e}-05$ & 0.000602923 & 2.046865 \\
\hline CD4 & 920 & -0.58506 & 11.88188 & -4.47755 & $7.60948902049038 \mathrm{e}-05$ & 0.001028147 & 1.376615 \\
\hline CXCL10 & 3627 & 1.631283 & 8.848907 & 4.345596 & 0.000113 & 0.001370411 & 1.001962 \\
\hline$C D 3 E$ & 916 & -0.97544 & 7.366428 & -4.20317 & 0.000171 & 0.001899072 & 0.601192 \\
\hline$J A K 2$ & 3717 & -0.48515 & 8.592857 & -4.11155 & 0.000224 & 0.00232649 & 0.345574 \\
\hline$C D 3 G$ & 917 & -1.20381 & 9.556972 & -3.91864 & 0.000392 & 0.003563749 & -0.18626 \\
\hline$J A K 1$ & 3716 & -0.59944 & 8.267208 & -3.91613 & 0.000395 & 0.003577495 & -0.1931 \\
\hline$I L 2$ & 3558 & -0.2942 & 6.071253 & -3.42899 & 0.001561 & 0.010073612 & -1.48885 \\
\hline$C D 3 D$ & 915 & -1.09394 & 10.94817 & -3.40904 & 0.001649 & 0.010483054 & -1.54022 \\
\hline$I L 8$ & 3576 & 0.60116 & 6.437018 & 2.758184 & 0.009156 & 0.038474696 & -3.1249 \\
\hline$T N F$ & 7124 & -0.55144 & 8.348166 & -2.12754 & 0.040454 & 0.115394645 & -4.44803 \\
\hline$I F N G$ & 3458 & 0.343729 & 6.456565 & 2.003927 & 0.05282 & 0.139890256 & -4.67741 \\
\hline$C D 274$ & 29126 & 0.287052 & 6.972572 & 1.595125 & 0.119624 & 0.252744144 & -5.35573 \\
\hline CTLA4 & 1493 & -0.34698 & 7.308087 & -1.46845 & 0.15086 & 0.297642476 & -5.53913 \\
\hline FOXP3 & 50943 & -0.21119 & 7.084321 & -1.11059 & 0.274272 & 0.448342193 & -5.98325 \\
\hline IDOI & 3620 & 0.280503 & 9.884179 & 0.692108 & 0.49341 & 0.657485806 & -6.35487 \\
\hline
\end{tabular}

Log FC: Log2(fold change); adjusted $p$-value: FDR (false discovery rate) $p$-value adjustment; B: B-statistics (log-odds that that gene is differentially expressed).

related to components of the immune system. Results are shown in Table IV. Interestingly, CD28 and the VSIR gene that encodes for VISTA (V-domain immunoglobulin suppressor of $\mathrm{T}$ cell activation) also known as C10orf54, a known immune regulatory receptor, were down-regulated in tumor tissues compared with normal tissues. CD28 and VISTA belong to the same family, CD28/B-7 gene family (22). CD274 that encodes for PD-L1 and CTLA-4 did not reach a statistically significant $p$-Value (adj. $p$-Value $=0.25$ and 0.29 , respectively).
Lower expression of VISTA in NSCLC has been reported before (23), with mRNA levels shown to have an inverse correlation with tumor mutation burden (TMB) in lung adenocarcinoma (24). Similarly, analysis of data from cBioPortal shows that VISTA (VSIR or C10orf54 gene) is altered in $0.9 \%$ of lung adenocarcinoma and $1.4 \%$ of lung squamous cell carcinoma. Survival analysis with KMPlotter (18) showed that C10orf54 high gene expression is associated with better survival in adenocarcinoma and squamous cell 
A
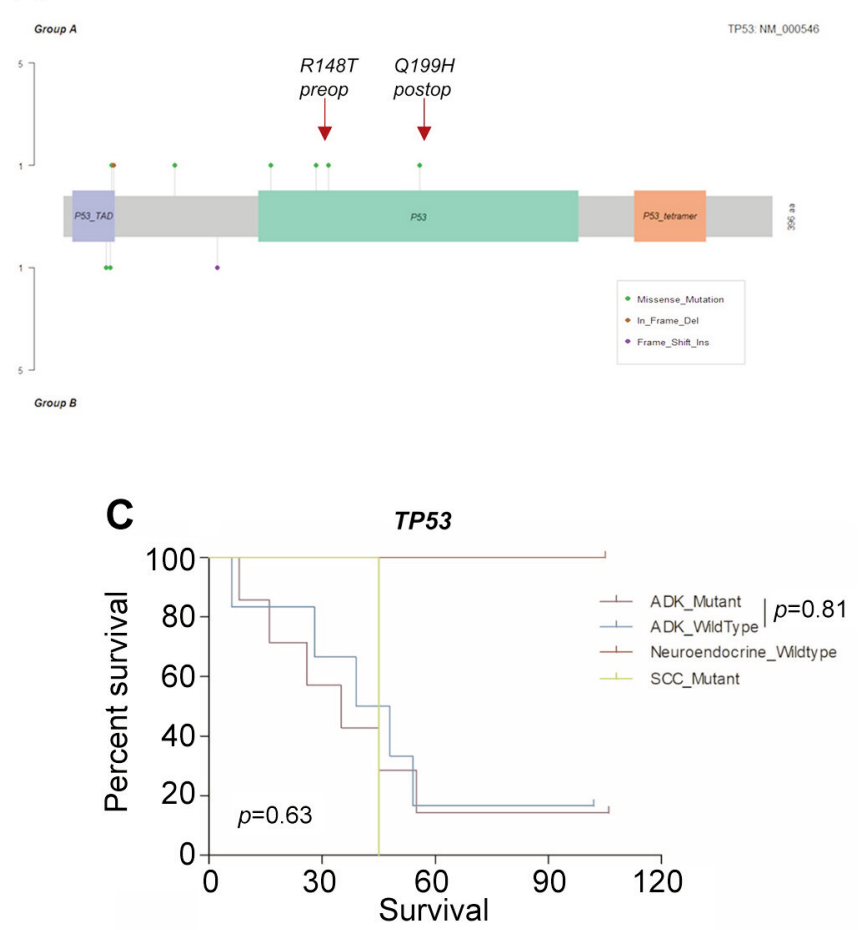

B

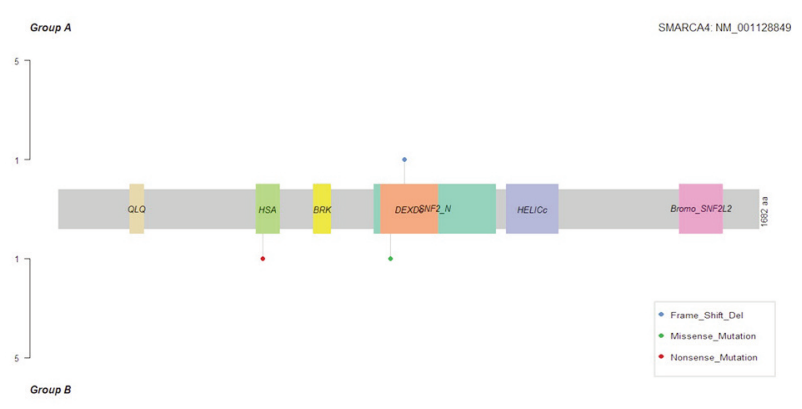

D

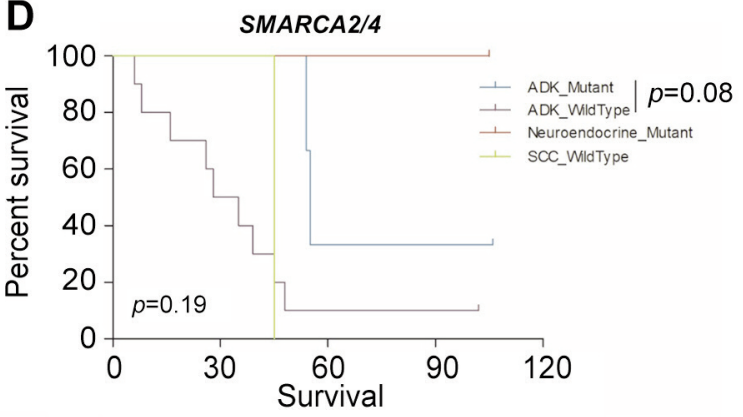

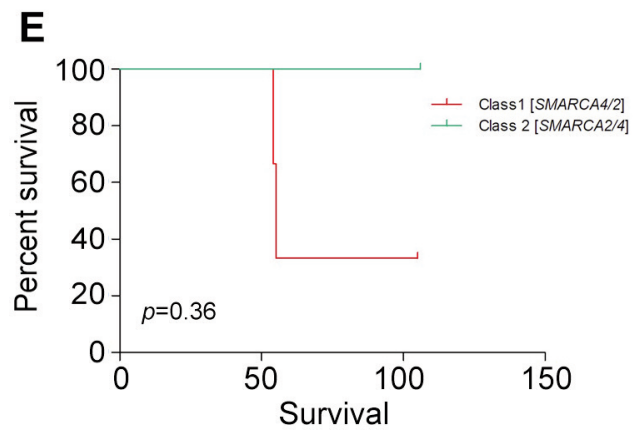

Figure 3. Distribution of variants and survival analysis in frequently mutated genes identified by WES. A) Lollipop plot showing mutations in TP53; only preoperative variants are represented with one exception marked on the graph with arrows where a different variant was detected in pre and postoperative sample; B) Lollipop plot showing mutations in SMARCA4 (only preoperative variants are represented); C) Survival curves comparing TP53 mutated vs wild type patients; D) Survival curves comparing SMARCA2/4 mutated vs wild type patients; E) Survival curves comparing SMARCA2/4 Class 1 and Class2 mutation.

carcinoma patients of all stages (Figure 4E and F). Statistical significance was still valid when analyzing adenocarcinoma and squamous cell carcinoma patients stage I ( $p$-Value $=0.012$ and 0.042 , respectively) but not the rest of the patients.

\section{Discussion}

In this study, we have analyzed pre and postoperative samples from NSCLC stage III (N2) patients, classified based on their response to platinum therapy in responders and non-responders with follow-up data that extended to seven years, by microarray and whole exome sequencing (WES). We identified seven SNPs in five genes that segregated patients in two groups according to their response.

We found that a homozygous genotype for rs 99005892 in the $S L F N 12 L$ gene was associated with better survival, in the whole cohort. SLFN12L (Schlafen Family Member 12 Like) belongs to SLFN family of molecules that are induced by interferon type I (IFNa) (25). In lung cancer, SLFN12, a paralog of $S L F N 12 L$, has been shown to play a favorable role 


\section{A}

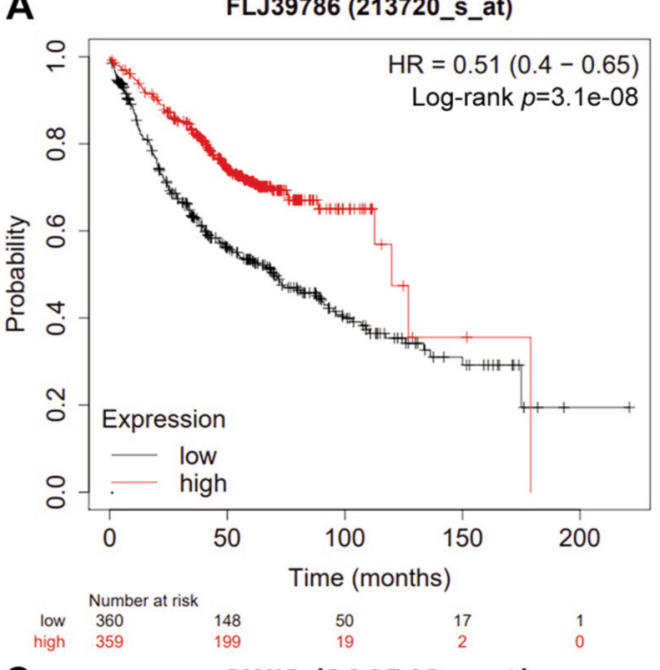

C SWI2 (206542_s_at)
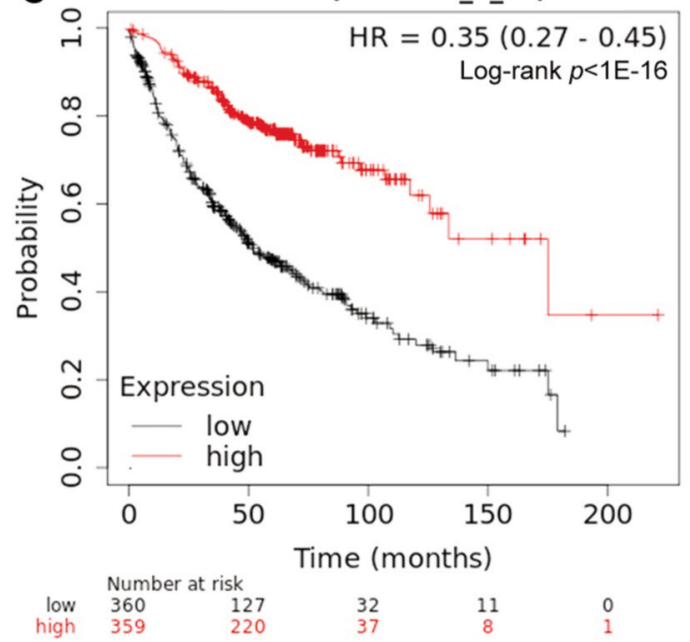

E C10orf54 (225372_at)

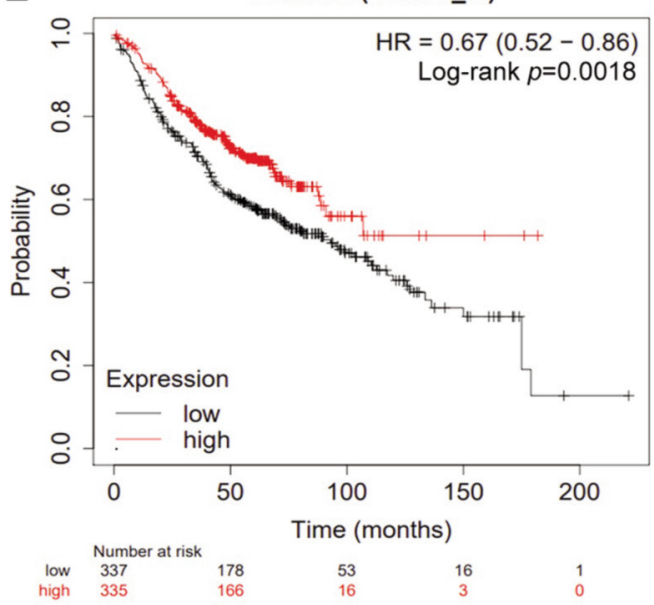

B
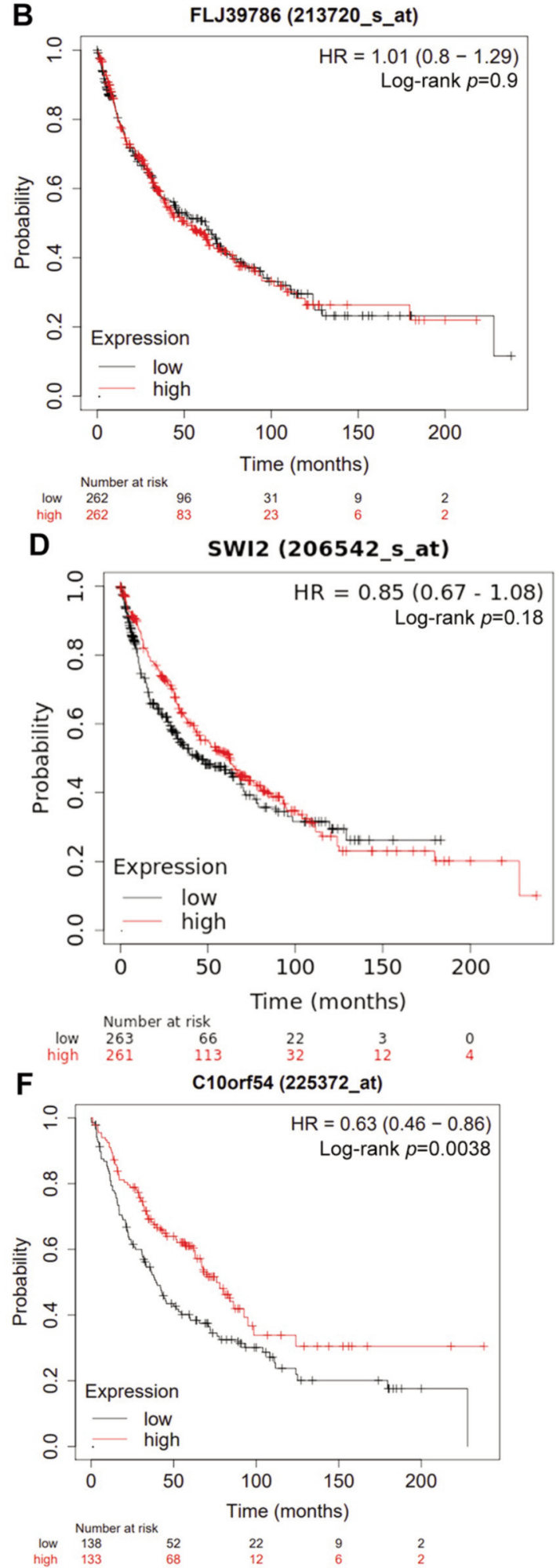

Figure 4. Kaplan-Meier survival curves in lung cancer patients from KMPlotter data. A) SMARCA4 (FLJ39786) gene expression in adenocarcinoma patients (all stages); B) SMARC4 (FLJ39786) gene expression in squamous cell carcinoma (all stages); C) SMARCA2 (SWI2) gene expression in adenocarcinoma patients (all stages); D) SMARC2 (SWI2) gene expression in squamous cell carcinoma (all stages); E) C10orf54 (VSIR) gene expression in adenocarcinoma patients (all stages); F) C10orf54 (VSIR) gene expression in squamous cell carcinoma (all stages) (gene names were used as shown by KMPlotter in all graphs). 
in lung cancer adenocarcinoma by modulating of c-myc expression; patients with higher expression of SLFN12 show a better survival (26). It has been shown the SLFN12L protein expression increases in Helicobacter pylori infected patients with intestinal metaplasia, a precursor of gastric cancer, and marks a population of myeloid-derived suppressor cells (MDSCs) (27). It has also been suggested that in humans, SLFN12L might be used as a biomarker for a subset of the population that might benefit from treatment with Hedgehog ( $\mathrm{HH})$ antagonists (28). Whether this is applicable to NSCLC patients remains to be clarified, but points to encouraging results involving SLFN family in cancer and in NSCLC particularly. Further studies are needed to better elucidate their involvement in cancer onset and progression especially in the modulation of immune responses.

Further, we have investigated the presence of mutations in known NSCLC genes and identified mutations in the SWI/SNF complex (in SMARCA4, SMARCA2 and ARIDIA genes) as the most frequent in the responder group of patients (4/6 patients, $66.7 \%$ ). In our cohort, SMARCA2/4 mutations were more common among the responder group of patients (group B). We also observed a mutation in another component of SWI/SNF complex, ARIDIA, that was also detected in a group B patient. Interestingly, two patients from the alive patients group (one patient with adenocarcinoma and one with neuroendocrine tumour) had two SMARCA4 mutations, one missense and one stop mutation, respectively. It is tempting to speculate that the presence of the SWI/SNF mutations in these patients might be associated with their favorable response to platinum therapy.

Members of the SWI/SNF family have been implicated in DNA repair and genome instability (29). The genes encoding different members of the family are commonly mutated in different tumours, making this complex one of the most frequently altered in cancer (30). SMARCA4/BRG1 and SMARCA2/BRM are ATP-dependent helicases $(19,31)$, sharing $75 \%$ identity at the protein level.

It was shown that NSCLC patients (stage 3B+) with SMARCA4 homozygous deletions situated in the SNF2 domain or the helicase domain and with no $E G F R, A L K$, $R O S 1$ or $B R A F$ alterations had a worse outcome compared with patients with wild-type SMARCA4 (19). More recently, deficiencies in components of SWI/SNF complex were reported to confer sensitivity to immunotherapy $(32,33)$. Bell et al. (34) showed that in NSCLC, patients with low SMARCA4/BRG1 expression who received adjuvant cisplatin/vinorelbine therapy had an improved 5-year disease specific survival, suggesting it to be a novel predictive biomarker for sensitivity to platinum-based chemotherapy in NSCLC. Our microarray data did not show any statistically significant difference between tumor and normal tissue for SMARCA4, but the significant difference was present for SMARCA2 (Table III).
Analysis of pre and postoperative samples identified an acquired KRAS G13C hotspot mutation in one postoperative lung adenocarcinoma sample. We did not detect this mutation in the paired pre-operative sample and it is possible that the mutation in the preoperative sample to have been diluted out by presence of non-tumour cells that led to the alteration not being detected in this sample. Nevertheless, detection of this mutation in a postoperative sample (after chemotherapy) is something to investigate further in a bigger cohort of patients.

We have investigated the microarray data for expression of important immune system components and identified $C D 28$ and VISTA (V-domain Ig-containing suppressor of T cell activation, VSIR/C10orf54 gene, VISTA/PD-1H) as significantly downregulated in tumor versus normal tissues. PD-L1 (CD274) and CTLA-4 were not significantly differentially expressed between tissues (Table IV). VISTA, is a member of the immunoglobulin (Ig) superfamily, with homology to programmed death ligand 1 (PD-L1) (35). In tumors, high expression of VISTA was correlated with better overall survival than low expression, including in NSCLC (23) and was also associated with high number of CD8+ TILs (35). It was suggested that VISTA plays an immunomodulatory role in NSCLC (24).

NSCLC is known to have a high TMB that increases the neo-antigen production and immune system recognition that might correlate with response to immune checkpoint inhibition therapy (36). Along with inhibition of PD-1/PD-L1 and CTLA4, VISTA has become as equally important target in overcoming immune resistance $(37,38)$ with drugs like CA170 showing effective results in a lung cancer mouse model (39).

In conclusion, in this study we highlighted important findings related to NSCLC stage III (N2) patients' response to chemotherapy and improved survival after multimodal treatment that may support new therapeutic avenues.

\section{Conflicts of Interest}

The Authors declare no conflicts of interest.

\section{Authors' Contributions}

AN processed the samples, extracted DNA, assessed samples' quality, prepared samples for shipping and analyzed the results received from BGI; AL was involved in histopathological review of the samples; VL was involved in sample processing; SOD, IP and $\mathrm{MG}$ were involved in the implementation and coordination of the study; MEG, Al.N and SB were involved in clinical data review; WK and MA were involved in sample collection; RT and SD analyzed the microarray data; MG planned the study, AN and MG wrote the manuscript with the assistance and final approval of all Authors.

\section{Acknowledgements}

The research presented in this article was supported by Funding Contract no. 211 with OI - ANCS signed on 20.07.2010, within POS CE Operational Programme, Priority Axis 2 - CDI 
competitiveness - Major Field of Intervention D.2.1. "Researchdevelopment in partnerships between research-development universities/institutes and enterprises for result attainment applicable in economy", Operation 2.1.2.: "High level scientific CD projects with specialists from abroad", Project title Gene Profile Of NonSmall Cell Primitive Bronchopulmonary Cancers And Invasion Of Mediastinal Lymph Nodes, Project number/Code SMIS 692/12650, undertaken between 20.07.2010 - 30.06.2014.

\section{References}

1 Ruckdeschel JC: Combined modality therapy of non-small cell lung cancer. Semin Oncol 24(4): 429-439, 1997. PMID: 9280223.

2 Stinchcombe TE, Fried D, Morris DE and Socinski MA: Combined modality therapy for stage III non-small cell lung cancer. Oncologist 11(7): 809-823, 2006. PMID: 16880240. DOI: $10.1634 /$ theoncologist.11-7-809

3 Albain KS, Swann RS, Rusch VW, Turrisi AT 3rd, Shepherd FA, Smith C, Chen Y, Livingston RB, Feins RH, Gandara DR, Fry WA, Darling G, Johnson DH, Green MR, Miller RC, Ley J, Sause WT and Cox JD: Radiotherapy plus chemotherapy with or without surgical resection for stage III non-small-cell lung cancer: a phase III randomised controlled trial. Lancet 374(9687): 379-386, 2009. PMID: 19632716. DOI: 10.1016/S0140-6736(09)60737-6

4 Sause W, Kolesar P, Taylor S IV, Johnson D, Livingston R, Komaki R, Emami B, Curran W Jr, Byhardt R, Dar AR and Turrisi A 3rd: Final results of phase III trial in regionally advanced unresectable non-small cell lung cancer: Radiation Therapy Oncology Group, Eastern Cooperative Oncology Group, and Southwest Oncology Group. Chest 117(2): 358-364, 2000. PMID: 10669675. DOI: 10.1378/chest.117.2.358

5 Roth JA, Fossella F, Komaki R, Ryan MB, Putnam JB Jr, Lee JS, Dhingra H, De Caro L, Chasen M and McGavran M: A randomized trial comparing perioperative chemotherapy and surgery with surgery alone in resectable stage IIIA non-smallcell lung cancer. J Natl Cancer Inst 86(9): 673-680, 1994. PMID: 8158698. DOI: $10.1093 /$ jnci/86.9.673

6 Albain KS, Rusch VW, Crowley JJ, Rice TW, Turrisi AT 3rd, Weick JK, Lonchyna VA, Presant CA, McKenna RJ and Gandara DR: Concurrent cisplatin/etoposide plus chest radiotherapy followed by surgery for stages IIIA (N2) and IIIB non-small-cell lung cancer: mature results of Southwest Oncology Group phase II study 8805. J Clin Oncol 13(8): 1880-1892, 1995. PMID: 7636530. DOI: $10.1200 / \mathrm{JCO} .1995 .13 .8 .1880$

7 Rosell R, Gómez-Codina J, Camps C, Maestre J, Padille J, Cantó A, Mate JL, Li S, Roig J and Olazábal A: A randomized trial comparing preoperative chemotherapy plus surgery with surgery alone in patients with non-small-cell lung cancer. N Engl J Med 330(3): 153-158, 1994. PMID: 8043059. DOI: 10.1056/ NEJM199401203300301

8 Strauss GM, Langer MP, Elias AD, Skarin AT and Sugarbaker DJ: Multimodality treatment of stage IIIA non-small-cell lung carcinoma: a critical review of the literature and strategies for future research. J Clin Oncol 10(5): 829-838, 1992. PMID: 1314892. DOI: $10.1200 / J C O .1992 .10 .5 .829$

9 Albain KS: Induction chemotherapy with/without radiation followed by surgery in stage III non-small-cell lung cancer. Oncology (Williston Park) 11(9 Suppl 9): 51-57, 1997. PMID: 9330409.
10 Rosell R, Gómez-Codina J, Camps C, Javier Sánchez J, Maestre J, Padilla J, Cantó A, Abad A and Roig J: Preresectional chemotherapy in stage IIIA non-small-cell lung cancer: a 7-year assessment of a randomized controlled trial. Lung Cancer 26(1): 7-14, 1999. PMID: 10574676. DOI: 10.1016/s0169-5002(99)00045-8

11 Martini N, Kris MG, Flehinger BJ, Gralla RJ, Bains MS, Burt ME, Heelan R, McCormack PM, Pisters KM and Rigas JR: Preoperative chemotherapy for stage IIIa (N2) lung cancer: the Sloan-Kettering experience with 136 patients. Ann Thorac Surg 55(6): 1365-73; discussion 1373-4, 1993. PMID: 8390230. DOI: 10.1016/0003-4975(93)91072-u

12 Goldberg M and Burkes RL: Induction chemotherapy for stage IIIA unresectable non-small cell lung cancer: the Toronto experience and an overview. Semin Surg Oncol 9(2): 108-113, 1993. PMID: 8387687. DOI: 10.1002/ssu.2980090208

13 Remark R, Lupo A, Alifano M, Biton J, Ouakrim H, Stefani A, Cremer I, Goc J, Régnard JF, Dieu-Nosjean MC and Damotte D: Immune contexture and histological response after neoadjuvant chemotherapy predict clinical outcome of lung cancer patients. Oncoimmunology 5(12): e1255394, 2016. PMID: 28123901. DOI: $10.1080 / 2162402 X .2016 .1255394$

14 Stefani A, Alifano M, Bobbio A, Grigoroiu M, Jouni R, Magdeleinat $\mathrm{P}$ and Regnard JF: Which patients should be operated on after induction chemotherapy for N2 non-small cell lung cancer? Analysis of a 7-year experience in 175 patients. J Thorac Cardiovasc Surg 140(2): 356-363, 2010. PMID: 20381815. DOI: $10.1016 /$ j.jtcvs.2010.02.018

15 Grigoroiu M, Tagett R, Draghici S, Dima S, Nastase A, Florea R, Sorop A, Ilie V, Bacalbasa N, Tica V, Laszlo V, MansuetLupo A, Damotte D, Klepetko W, Popescu I and Regnard JF: Gene-expression profiling in non-small cell lung cancer with invasion of mediastinal lymph nodes for prognosis evaluation. Cancer Genomics Proteomics 12(5): 231-242, 2015. PMID: 26417026.

16 Nastase A, Lupo A, Laszlo V, Damotte D, Dima S, Canny E, Alifano M, Popescu I, Klepetko W and Grigoroiu M: Platinum drug sensitivity polymorphisms in stage III non-small cell lung cancer with invasion of mediastinal lymph nodes. Cancer Genomics Proteomics 17(5): 587-595, 2020. PMID: 32859637. DOI: $10.21873 / \mathrm{cgp} .20215$

17 Schoenfeld AJ, Bandlamudi C, Lavery JA, Montecalvo J, Namakydoust A, Rizvi H, Egger J, Concepcion CP, Paul S, Arcila ME, Daneshbod Y, Chang J, Sauter JL, Beras A, Ladanyi M, Jacks T, Rudin CM, Taylor BS, Donoghue MTA, Heller G, Hellmann MD, Rekhtman N and Riely GJ: The genomic landscape of SMARCA4 alterations and associations with outcomes in patients with lung cancer. Clin Cancer Res 26(21): 5701-5708, 2020. PMID: 32709715. DOI: 10.1158/10780432.CCR-20-1825

18 Győrffy B, Surowiak P, Budczies J and Lánczky A: Online survival analysis software to assess the prognostic value of biomarkers using transcriptomic data in non-small-cell lung cancer. PLoS One 8(12): e82241, 2013. PMID: 24367507. DOI: 10.1371/journal.pone.0082241

19 Fernando TM, Piskol R, Bainer R, Sokol ES, Trabucco SE, Zhang Q, Trinh H, Maund S, Kschonsak M, Chaudhuri S, Modrusan Z, Januario $T$ and Yauch RL: Functional characterization of SMARCA4 variants identified by targeted exome-sequencing of 131,668 cancer patients. Nat Commun 11(1): 5551, 2020. PMID: 33144586. DOI: $10.1038 / \mathrm{s} 41467-020-19402-8$ 
20 Fillmore CM, Xu C, Desai PT, Berry JM, Rowbotham SP, Lin YJ, Zhang H, Marquez VE, Hammerman PS, Wong KK and Kim CF: EZH2 inhibition sensitizes BRG1 and EGFR mutant lung tumours to TopoII inhibitors. Nature 520(7546): 239-242, 2015. PMID: 25629630. DOI: 10.1038/nature 14122

21 Matsubara D, Kishaba Y, Ishikawa S, Sakatani T, Oguni S, Tamura T, Hoshino H, Sugiyama Y, Endo S, Murakami Y, Aburatani H, Fukayama M and Niki T: Lung cancer with loss of BRG1/BRM, shows epithelial mesenchymal transition phenotype and distinct histologic and genetic features. Cancer Sci 104(2): 266-273, 2013. PMID: 23163725. DOI: $10.1111 /$ cas.12065

22 Slater BT, Han X, Chen L and Xiong Y: Structural insight into T cell coinhibition by PD-1H (VISTA). Proc Natl Acad Sci USA 117(3): 1648-1657, 2020. PMID: 31919279. DOI: 10.1073/pnas. 1908711117

23 Huang X, Zhang X, Li E, Zhang G, Wang X, Tang T, Bai X and Liang T: VISTA: an immune regulatory protein checking tumor and immune cells in cancer immunotherapy. J Hematol Oncol 13(1): 83, 2020. PMID: 32600443. DOI: 10.1186/s13045-02000917-y

24 Villarroel-Espindola F, Yu X, Datar I, Mani N, Sanmamed M, Velcheti V, Syrigos K, Toki M, Zhao H, Chen L, Herbst RS and Schalper KA: Spatially resolved and quantitative analysis of VISTA/PD-1H as a novel immunotherapy target in human nonsmall cell lung cancer. Clin Cancer Res 24(7): 1562-1573, 2018 PMID: 29203588. DOI: 10.1158/1078-0432.CCR-17-2542

25 Geserick P, Kaiser F, Klemm U, Kaufmann SH and Zerrahn J: Modulation of $\mathrm{T}$ cell development and activation by novel members of the Schlafen (slfn) gene family harbouring an RNA helicase-like motif. Int Immunol 16(10): 1535-1548, 2004. PMID: 15351786. DOI: 10.1093/intimm/dxh155

26 Al-Marsoummi S, Pacella J, Dockter K, Soderberg M, Singhal SK, Vomhof-DeKrey EE and Basson MD: Schlafen 12 is prognostically favorable and reduces $\mathrm{C}-\mathrm{Myc}$ and proliferation in lung adenocarcinoma but not in lung squamous cell carcinoma. Cancers (Basel) 12(10): 2738, 2020. PMID: 32987632. DOI: 10.3390/cancers 12102738

27 Ding L, Hayes MM, Photenhauer A, Eaton KA, Li Q, OcadizRuiz R and Merchant JL: Schlafen 4-expressing myeloid-derived suppressor cells are induced during murine gastric metaplasia. J Clin Invest 126(8): 2867-2880, 2016. PMID: 27427984. DOI: $10.1172 /$ JCI82529

28 Merchant JL and Ding L: Hedgehog signaling links chronic inflammation to gastric cancer precursor lesions. Cell Mol Gastroenterol Hepatol 3(2): 201-210, 2017. PMID: 28275687. DOI: $10.1016 /$ j.jcmgh.2017.01.004

29 Brownlee PM, Meisenberg C and Downs JA: The SWI/SNF chromatin remodelling complex: Its role in maintaining genome stability and preventing tumourigenesis. DNA Repair (Amst) 32: 127-133, 2015. PMID: 25981841. DOI: 10.1016/j.dnarep. 2015.04.023

30 Kadoch C, Hargreaves DC, Hodges C, Elias L, Ho L, Ranish J and Crabtree GR: Proteomic and bioinformatic analysis of mammalian SWI/SNF complexes identifies extensive roles in human malignancy. Nat Genet 45(6): 592-601, 2013. PMID: 23644491. DOI: $10.1038 /$ ng.2628

31 Mashtalir N, D'Avino AR, Michel BC, Luo J, Pan J, Otto JE, Zullow HJ, McKenzie ZM, Kubiak RL, St Pierre R, Valencia AM, Poynter SJ, Cassel SH, Ranish JA and Kadoch C: Modular organization and assembly of SWI/SNF family chromatin remodeling complexes. Cell 175(5): 1272-1288.e20, 2018. PMID: 30343899. DOI: 10.1016/j.cell.2018.09.032

32 Mittal P and Roberts CWM: The SWI/SNF complex in cancer biology, biomarkers and therapy. Nat Rev Clin Oncol 17(7): 435-448, 2020. PMID: 32303701. DOI: 10.1038/s41571-0200357-3

33 Zhou M, Yuan J, Deng Y, Fan X and Shen J: Emerging role of SWI/SNF complex deficiency as a target of immune checkpoint blockade in human cancers. Oncogenesis 10(1): 3, 2021. PMID: 33419967. DOI: 10.1038/s41389-020-00296-6

34 Bell EH, Chakraborty AR, Mo X, Liu Z, Shilo K, Kirste S, Stegmaier P, McNulty M, Karachaliou N, Rosell R, Bepler G, Carbone DP and Chakravarti A: SMARCA4/BRG1 is a novel prognostic biomarker predictive of cisplatin-based chemotherapy outcomes in resected non-small cell lung cancer. Clin Cancer Res 22(10): 2396-2404, 2016. PMID: 26671993. DOI: 10.1158/1078-0432.CCR-15-1468

35 He XL, Zhou Y, Lu HZ, Li QX and Wang Z: Prognostic value of VISTA in solid tumours: a systematic review and metaanalysis. Sci Rep 10(1): 2662, 2020. PMID: 32060343. DOI: 10.1038/s41598-020-59608-w

36 Sholl LM, Hirsch FR, Hwang D, Botling J, Lopez-Rios F, Bubendorf L, Mino-Kenudson M, Roden AC, Beasley MB, Borczuk A, Brambilla E, Chen G, Chou TY, Chung JH, Cooper WA, Dacic S, Lantuejoul S, Jain D, Lin D, Minami Y, Moreira A, Nicholson AG, Noguchi M, Papotti M, Pelosi G, Poleri C, Rekhtman N, Tsao MS, Thunnissen E, Travis W, Yatabe Y, Yoshida A, Daigneault JB, Zehir A, Peters S, Wistuba II, Kerr KM and Longshore JW: The promises and challenges of tumor mutation burden as an immunotherapy biomarker: a perspective from the international association for the study of lung cancer pathology committee. J Thorac Oncol 15(9): 1409-1424, 2020. PMID: 32522712. DOI: 10.1016/j.jtho.2020.05.019

37 Yuan L, Tatineni J, Mahoney KM and Freeman GJ: VISTA: A mediator of quiescence and a promising target in cancer immunotherapy. Trends Immunol 42(3): 209-227, 2021. PMID: 33495077. DOI: $10.1016 /$ j.it.2020.12.008

38 Gao J, Ward JF, Pettaway CA, Shi LZ, Subudhi SK, Vence LM, Zhao H, Chen J, Chen H, Efstathiou E, Troncoso P, Allison JP, Logothetis CJ, Wistuba II, Sepulveda MA, Sun J, Wargo J, Blando $J$ and Sharma P: VISTA is an inhibitory immune checkpoint that is increased after ipilimumab therapy in patients with prostate cancer. Nat Med 23(5): 551-555, 2017. PMID: 28346412. DOI: $10.1038 / \mathrm{nm} .4308$

39 Pan J, Chen Y, Zhang Q, Khatun A, Palen K, Xin G, Wang L, Yang C, Johnson BD, Myers CR, Sei S, Shoemaker RH, Lubet RA, Wang Y, Cui W and You M: Inhibition of lung tumorigenesis by a small molecule CA170 targeting the immune checkpoint protein VISTA. Commun Biol 4(1): 906, 2021. PMID: 34302042. DOI: 10.1038/s42003-021-02381-x 